\title{
Absence of chromosome damage in human lymphocytes exposed to allopurinol and oxipurinol
}

\section{In vivo and in vitro studies}

\author{
A. C. STEVENSON,* S. R. SILCOCK, $\dagger$ And J. T. SCOTT $\ddagger$
}

From the Department of Pathology, Raigmore Hospital, Inverness;* Department of Clinical Investigation, Wellcome Foundation, Ltd., London; $\dagger$ and Charing Cross Hospital and Kennedy Institute of Rheumatology, London $\ddagger$

\begin{abstract}
Stevenson, A. C., Silcock, S. R., and Scott, J. T. (1976). Annals of the Rheumatic Diseases, 35, 143-147. Absence of chromosome damage in human lymphocytes exposed to allopurinol and oxipurinol. In vivo and in vitro studies. The biochemical evidence against incorporation of the purine analogues, allopurinol and oxipurinol, into nucleic acids is reviewed. Cytological experiments have been carried out to investigate the possibility that chromosomal damage might result from exposure of human lymphocytes to these drugs. Lymphocytes from 19 patients receiving allopurinol and one receiving oxipurinol were examined for the presence of chromatid aberrations during metaphase, and lymphocytes from untreated subjects were similarly studied during in vitro exposure to the drugs. The low frequency of aberrations observed was well within normal limits, and it is concluded that allopurinol and oxipurinol have no deleterious effects on chromosome structure.
\end{abstract}

Allopurinol is used extensively in the management of conditions associated with excess body urate, e.g. gouty arthritis. It reduces urate formation by inhibiting xanthine oxidase, and hence blocking the conversion of hypoxanthine and xanthine to urate/ uric acid, i.e. the final steps in the purine catabolic pathway in man. It also reduces de novo purine synthesis by a feedback mechanism. The pharmacology of allopurinol and its therapeutically active metabolite, oxipurinol, has been described in depth by Rundles and others (1963), Elion (1966), Emmerson (1966), Hitchings (1966, 1969), Chalmers and others (1968), and Kelley and Wyngaarden (1972).

Allopurinol and oxipurinol are structural analogues of the purines xanthine and hypoxanthine (Figure). The theoretical possibility has therefore been considered that allopurinol or its metabolites might be incorporated into nucleic acids, or interfere with

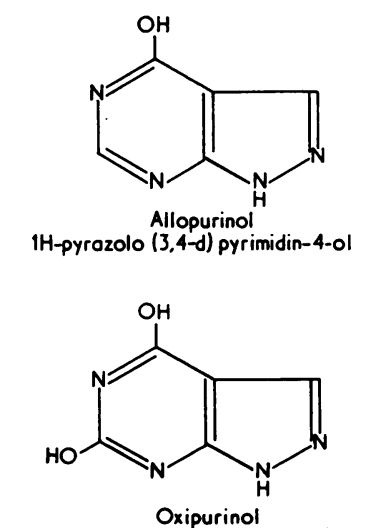

1H-pyrazolo (3,4-d) pyrimidin-4, 6-diol<smiles>Oc1ncnc2[nH]cnc12</smiles><smiles>Oc1nc(O)c2nc[nH]c2n1</smiles>

Xonthine

FIGURE Structure of allopurinol and oxipurinol 
nucleic acid replication, and that long-term therapy with allopurinol could have genetic repercussions.

Nucleic acids are polymers of nucleoside monophosphates, i.e. base + sugar + one phosphate group. To permit incorporation of purine or pyrimidine bases, these must first be converted into the corresponding nucleoside triphosphates (Bell, Davidson, and Emslie-Smith, 1972). This is an essential step in the synthesis of both deoxyribonucleic acid (DNA) and ribonucleic acid (RNA). In order to verify incorporation of an analogue base, it would be necessary to identify the analogue in formed nucleic acids, and also to demonstrate formation of the corresponding precursors-in this case, nucleoside mono-, di-, and triphosphate derivatives of allopurinol or its metabolites. Failure to find such evidence would make the possibility of incorporation extremely remote.

Previous in vitro and in vivo studies showed no incorporation of $6-{ }^{14} \mathrm{C}$ allopurinol into the nucleic acids of cultured human fibroblasts (Kelley and Wyngaarden, 1970) or livers of mice given $1 \mathrm{mg}$ intraperitoneally (Elion and others, 1966). The nucleoside monophosphates of allopurinol and oxipurinol have been synthesized enzymatically in vitro (Krenitsky and others, 1967; Fyfe, Miller, and Krenitsky, 1973). They were shown in micromolar quantities $\left(<10^{-9}-10^{-6} \mathrm{~mol} / \mathrm{l}\right)$ in the liver and kidneys of rats given large $(50 \mathrm{mg} / \mathrm{kg})$ intravenous doses of $6-{ }^{14} \mathrm{C}$ allopurinol and oxipurinol, but there was no evidence for the presence of the corresponding nucleoside di- and triphosphates (Nelson and others, 1973).

Nelson and Elion (1975) have recently provided virtually conclusive evidence against the incorporation of allopurinol or its metabolites into nucleic acids. They calculated that, had incorporation occurred, the amounts involved must have been less than 1 molecule of analogue base per $5 \times 10^{6}$ normal bases in RNA, and less than 1 molecule per $10^{7}$ normal bases in DNA. This is below biochemically detectable limits.

Any instability in nucleic acids resulting from the exposure of cells to purine or pyrimidine analogues might be manifested as disturbed chromosomal behaviour, e.g. an increased frequency of chromosome breaks during the mitotic cycle. In the absence of any reports regarding the effects of allopurinol and oxipurinol on chromosomes, either in the replicating or nonreplicating phases of cell division, the following study was undertaken.

\section{Material and methods}

The study was designed to investigate the effect of allopurinol and oxipurinol on human chromosomes. For practical reasons explained in the discussion, the experiments were conducted on peripheral lymphocytes. These cells divide infrequently in vivo, but can be stimulated to enter mitosis in culture by phytohaemagglutinins (PHA). The first experiments (in vivo studies) were done on lymphocytes taken from patients treated with allopurinol or oxipurinol, and thus exposed to these drugs in vivo. The second series (in vitro studies) was conducted on lymphocytes from untreated subjects, stimulated to divide in the presence of allopurinol and/or oxipurinol. A microculture technique, similar to that of Arakaki and Sparkes (1963), was used for both in vivo and in vitro experiments, in which $0.5 \mathrm{ml}$ whole blood and $1 \mathrm{ml}$ plasma were added to $4 \mathrm{ml}$ Eagle's Minimal Essential Medium with PHA. Colcemid was added 3 hours before harvesting to arrest cells in metaphase for preparing chromosome spreads.

\section{IN VIVO STUDIES}

Lymphocytes were cultured from 20 patients treated for hyperuricaemia and gout, 19 of them with allopurinol and one with oxipurinol (because of skin sensitivity to allopurinol). All were responding satisfactorily to therapy. Dosage and duration of treatment were as follows: allopurinol $200-600 \mathrm{mg}$ daily for a mean period of 40 months; oxipurinol $600 \mathrm{mg}$ daily for 55 months. At the time of sampling, sera of all patients concerned in the study showed a peak on chromatograms identifiable as oxipurinol.* After a culture period of $\mathbf{4 8}$ hours, metaphase chromosomes were examined for chromatid and isochromatid gaps and breaks.

\section{IN VITRO STUDIES}

Lymphocytes were taken from a pool of normal donors. The chromosomal behaviour of these lymphocytes was well established from previous studies. They were cultured in the presence of $10,40,80$, and $100 \mu \mathrm{g} / \mathrm{ml}$ allopurinol alone; $100 \mu \mathrm{g} / \mathrm{ml}$ allopurinol plus $100 \mu \mathrm{g} / \mathrm{ml}$ oxipurinol; $100 \mu \mathrm{g} / \mathrm{ml}$ allopurinol plus $50 \mu \mathrm{g} / \mathrm{ml}$ amylobarbitone; and $200 \mu \mathrm{g} / \mathrm{ml}$ oxipurinol plus $50 \mu \mathrm{g} / \mathrm{ml}$ amylobarbitone. The barbiturate experiments were included as a follow-up to previous studies on drug-induced modifications of chromosome behaviour, and are of no immediate relevance to the present study (Stevenson, San Roman, and Patel, 1973). Allopurinol and oxipurinol were dissolved in $\mathrm{N} / 15$ sodium hydroxide $(\mathrm{NaOH})$ before being added to the cultures. The amount of $\mathrm{NaOH}$ needed to dissolve the highest drug concentrations was added to control cultures. Both test and control cultures were corrected to pH 7 by gassing with carbon dioxide. After a culture period of 72 hours metaphase chromosomes were examined for chromatid and isochromatid gaps or breaks.

\section{Results}

All results were compared with control values for this laboratory: 73 normal subjects with 7900 cells analysed showed frequencies for chromatid gaps, chromatid breaks, isochromatid gaps, and isochromatid breaks of $0.62 \%, 0.42 \%, 0.42 \%$ and $0.44 \%$, respectively (see Table III).

* The original method based on high pressure liquid chromatography (HPLC) was capable of qualitative oxipurinol determination only. A more complex HPLC method is currently being developed, and it is hoped to assign quantitative levels of both allopurinol and oxipurino to these samples in the near future (A. Bye and M. E. Brown, personal communication, 1975). 
IN VIVO STUDIES

One hundred metaphase spreads were analysed for each of the 20 patients. No chromosomal aberrations attributable to damage in vivo were found. There was a low frequency of chromatid type aberrations attributable to damage in culture, but this was well within the normal limits. The detailed results are set out in Tables I and III.

\section{IN VITRO STUDIES}

One hundred metaphase spreads were examined from each culture. The findings showed no damage to chromosomes over and above control values during any stage of the cell cycle in the presence of allopurinol or oxipurinol, with or without the addition of amylobarbitone. The detailed results are set out in Table II.

\section{Discussion}

Chemical substances interfering with DNA replication can do so by causing structural damage to intact DNA, by inhibiting the incorporation of normal bases into DNA, or by themselves becoming incorporated in place of normal components. Whatever the mechanism, chromosome aberrations may well result. There is no evidence to suggest that allopurinol or oxipurinol could damage intact DNA (cf. radiomimetic agents such as nitrogen mustards). However, because they are purine analogues, they might in theory inhibit the incorporation of normal bases (cf. 6-mercaptopurine) or become incorporated as abnormal components (cf. 5-fluorodeoxyuridine). The majority of substances causing chromosomal damage probably do so during the DNA replication phase (' $S$ ' phase) of cell division. The best method for investigating such an effect is to allow cells to divide in the presence of the suspected substance(s) and then examine the chromosomes.

For in vivo studies, the preferred material would have been bone marrow cells, preferably sampled 12 to 24 hours after a single large dose of drug, since these cells have a rapid turnover (about once every 36 hours). However, sampling of bone marrow involves bone puncture, whereas peripheral lymphocytes are both readily accessible and easy to culture. They were therefore selected on practical grounds. Lymphocytes from peripheral blood exist almost exclusively in an interphase stage peculiar to these cells, in which there is minimum metabolic activity, conventionally termed ' $\mathrm{G}_{0}$ '. It is believed that they only divide in vivo about once every 3 years (Norman and others, 1965; Buckton, Smith, and Court Brown, 1967). It follows that, since the mean duration of treatment of the patients tested was about 38 months, most lymphocytes would probably have divided once during the period of treatment. In patients taking their drug regularly, any dividing cells would have been exposed to some level of oxipurinol. The plasma half-life of oxipurinol is 18-30 hours, whereas that of allopurinol is about 1 hour (Elion and others, 1966). Thus with daily administration of either drug, some

Table I Chromosome findings in 48-hour cultures of lymphocytes from 19 patients taking allopurinol and one (Case 13) taking oxipurinol. All patients were male except for Case 18.100 metaphases were scored for all patients except for Case 16 (only 97 good metaphases seen)

\begin{tabular}{|c|c|c|c|c|c|c|c|}
\hline \multirow[t]{2}{*}{ Case no. } & \multicolumn{2}{|c|}{ Chromatid } & \multicolumn{2}{|c|}{ Isochromatid } & \multirow{2}{*}{$\begin{array}{l}\text { Total } \\
\text { damaged } \\
\text { cells }\end{array}$} & \multirow{2}{*}{$\begin{array}{l}\text { Daily } \\
\text { dose } \\
\text { (mg) }\end{array}$} & \multirow{2}{*}{$\begin{array}{l}\text { Duration of } \\
\text { treatment } \\
(m)\end{array}$} \\
\hline & Gaps & Breaks & Gaps & Breaks & & & \\
\hline $\begin{array}{r}1 \\
2 \\
3 \\
4 \\
5 \\
6 \\
7 \\
8 \\
9 \\
10 \\
11 \\
12 \\
13 \\
14 \\
15 \\
16 \\
17 \\
18 \\
19 \\
20\end{array}$ & $\begin{array}{l}0 \\
0 \\
0 \\
0 \\
0 \\
0 \\
0 \\
0 \\
1 \\
1 \\
0 \\
2 \\
0 \\
0 \\
1 \\
0 \\
5 \\
1 \\
0 \\
0\end{array}$ & $\begin{array}{l}0 \\
0 \\
0 \\
0 \\
0 \\
0 \\
0 \\
0 \\
0 \\
0 \\
0 \\
0 \\
1 \\
0 \\
0 \\
2 \\
0 \\
2 \\
0 \\
2\end{array}$ & $\begin{array}{l}1 \\
0 \\
0 \\
0 \\
0 \\
0 \\
0 \\
0 \\
1 \\
0 \\
0 \\
0 \\
0 \\
0 \\
0 \\
0 \\
1 \\
2 \\
0 \\
0\end{array}$ & $\begin{array}{l}2 \\
0 \\
0 \\
0 \\
3 \\
0 \\
0 \\
0 \\
2 \\
1 \\
1 \\
0 \\
0 \\
1 \\
0 \\
0 \\
1 \\
0 \\
0 \\
0\end{array}$ & $\begin{array}{l}2 \\
0 \\
0 \\
0 \\
3 \\
0 \\
0 \\
0 \\
2 \\
1 \\
1 \\
0 \\
1 \\
1 \\
0 \\
2 \\
1 \\
2 \\
0 \\
2\end{array}$ & $\begin{array}{l}200 \\
200 \\
400 \\
400 \\
400 \\
600 \\
400 \\
400 \\
400 \\
400 \\
400 \\
400 \\
600 \\
400 \\
400 \\
400 \\
600 \\
300 \\
200 \\
400\end{array}$ & $\begin{array}{r}20 \\
91 \\
53 \\
41 \\
45 \\
36 \\
17 \\
30 \\
52 \\
41 \\
43 \\
28 \\
55 \\
36 \\
19 \\
24 \\
68 \\
2 \\
57 \\
10\end{array}$ \\
\hline Total & 11 & 7 & 5 & 11 & 18 & & \\
\hline
\end{tabular}


Table II Chromatid type aberrations in metaphases of lymphocytes from 72-hour cultures. The drugs shown $\frac{\square}{\omega}$. were present throughout culture

\begin{tabular}{|c|c|c|c|c|c|c|c|}
\hline \multirow[t]{3}{*}{ Experiment } & \multirow{3}{*}{$\begin{array}{l}\text { Drug and concentration } \\
(\mu g / m l)\end{array}$} & \multirow{3}{*}{$\begin{array}{l}\text { No. of } \\
\text { metaphases } \\
\text { analysed }\end{array}$} & \multicolumn{4}{|c|}{ Aberrations } & \multirow{3}{*}{$\begin{array}{l}\text { No. of } \\
\text { cells with } \\
\text { any damage } \\
\text { (breaks) }\end{array}$} \\
\hline & & & \multicolumn{2}{|c|}{ Chromatid } & \multicolumn{2}{|c|}{ Isochromatid } & \\
\hline & & & Gaps & Breaks & Gaps & Breaks & \\
\hline 1 & $\begin{array}{l}\text { Allopurinol } \\
10 \\
40 \\
80 \\
100\end{array}$ & $\begin{array}{l}100 \\
100 \\
100 \\
100\end{array}$ & $\begin{array}{l}\mathbf{0} \\
\mathbf{0} \\
\mathbf{0} \\
\mathbf{0}\end{array}$ & $\begin{array}{l}\mathbf{0} \\
\mathbf{1} \\
\mathbf{0} \\
\mathbf{0}\end{array}$ & $\begin{array}{l}\mathbf{0} \\
\mathbf{0} \\
\mathbf{0} \\
\mathbf{1}\end{array}$ & $\begin{array}{l}1 \\
0 \\
0 \\
0\end{array}$ & $\begin{array}{l}1 \\
1 \\
0 \\
0\end{array}$ \\
\hline \multirow[t]{2}{*}{2} & $\begin{array}{l}\text { Allopurinol } \\
100 \\
100 \\
\text { Oxipurinol }\end{array}$ & $\begin{array}{l}100 \\
100\end{array}$ & $\begin{array}{l}\mathbf{0} \\
\mathbf{0}\end{array}$ & $\begin{array}{l}0 \\
1\end{array}$ & $\begin{array}{l}\mathbf{0} \\
\mathbf{0}\end{array}$ & $\begin{array}{l}\mathbf{0} \\
\mathbf{0}\end{array}$ & $\begin{array}{l}0 \\
1\end{array}$ \\
\hline & $\begin{array}{l}200 \\
200\end{array}$ & $\begin{array}{l}100 \\
100\end{array}$ & $\begin{array}{l}0 \\
1\end{array}$ & $\begin{array}{l}\mathbf{0} \\
\mathbf{0}\end{array}$ & $\begin{array}{l}\mathbf{0} \\
\mathbf{1}\end{array}$ & $\begin{array}{l}\mathbf{0} \\
\mathbf{0}\end{array}$ & $\begin{array}{l}\mathbf{0} \\
\mathbf{0}\end{array}$ \\
\hline \multirow[t]{2}{*}{3} & $\begin{array}{l}\text { Allopurinol } \\
\quad 100 \\
\text { +amylobarbitone } \\
50\end{array}$ & 200 & 1 & 1 & $\mathbf{0}$ & $\mathbf{0}$ & 1 \\
\hline & $\begin{array}{l}\text { Oxipurinol } \\
200 \\
+ \text { +amylobarbitone } \\
50\end{array}$ & 200 & 0 & 1 & 0 & 0 & 1 \\
\hline
\end{tabular}

Table III Frequency of chromatid type aberrations in lymphocytes of 19 patients taking allopurinol and one patient taking oxipurinol: comparison with control cells (values expressed as percentages)

\begin{tabular}{|c|c|c|c|c|c|}
\hline & \multicolumn{4}{|c|}{ Frequency of aberrations ( $\%)$} & \multirow{3}{*}{$\begin{array}{l}\text { No. of cells } \\
\text { analysed }\end{array}$} \\
\hline & \multicolumn{2}{|c|}{ Chromatid } & \multicolumn{2}{|c|}{ Isochromatid } & \\
\hline & Gaps & Breaks & Gaps & Breaks & \\
\hline $\begin{array}{l}\text { Patients' } \\
\text { lymphocytes }\end{array}$ & 0.55 & $0 \cdot 25$ & $0 \cdot 25$ & 0.55 & 2000 \\
\hline $\begin{array}{l}\text { Control } \\
\text { lymphocytes from } 73 \text { subjects* }\end{array}$ & 0.62 & 0.42 & 0.42 & 0.44 & 7900 \\
\hline
\end{tabular}

* Laboratory reference standard.

oxipurinol would always be present in the plasma. As noted above, allopurinol or oxipurinol would not be expected to damage intact, nondividing DNA, hence chromosomal damage would be unlikely. Such damage would occur during the ' $S$ ' phase of cell division and be manifested as chromatid type damage. Unless it were sufficiently severe to cause cell death, most of it would be recognized in the first metaphase after culture. However, small deletions where a break had occurred during the in vivo division could well be missed in the first metaphase in culture if the acentric fragment had been absorbed. The 48-hour culture period ensured that the lymphocytes were in their first metaphase after leaving the body. For practical purposes, they can be considered to have divided in the absence of allopurinol or oxipurinol, except for small amounts of these drugs or their metabolites that might theoretically have been present intracellularly or carried over in the patients' sera. The absence of chromosome aberrations attributable to $\mathrm{\omega}$ allopurinol or oxipurinol in these preparations substantiated the concept that neither drug can cause 6 structural damage to intact DNA.

The in vitro study was designed to examine the effects of known concentrations of allopurinol and $T$ oxipurinol on dividing cells, although all but the lowest concentrations in these cultures were considerably higher than the maximum plasma concentrations likely to be achieved during therapy. Any chromosomal aberrations appearing after PHAstimulated cell division in culture would reflect effects exerted during DNA replication. The 72-hour 
culture period ensured that $70 \%$ of the lymphocytes examined were in their second metaphase and $30 \%$ in their first metaphase, i.e. they had undergone two ' $S$ ' phases and one ' $S$ ' phase, respectively. The absence of aberrations in these metaphase preparations indicated that allopurinol and oxipurinol have no deleterious effects on DNA replication.

\section{Conclusions}

The evidence from biochemical and cytological investigations strongly suggests that allopurinol and oxipurinol have no deleterious effects on DNA at any stage of the cell cycle. There appears to be no demonstrable grounds for anxiety regarding the mutagenic effects of allopurinol or oxipurinol.

The authors acknowledge with pleasure the collaboration of Dr. Walter Loebl and Dr. Ian Brewis in this study. Technical advice and assistance was given by Dr. G. B. Elion (Burroughs Wellcome, U.S.A.) and Dr. G. E. Lovatt (The Wellcome Foundation Ltd., London). The work was supported by the Arthritis \& Rheumatism Council.

\section{References}

Arakaki, D. T., and Sparkes, R. S. (1963) Cytogenetics, 2, 57 (Microtechnique for culturing leukocytes from whole blood)

Bell, G. H., Davidson, J. N., ANd Emslie-Smith, D. (1972) In 'Textbook of Physiology and Biochemistry', 8th ed., p. 349. Churchill Livingstone, Edinburgh and London

Buckton, K. E., Smith, P. G., AND Court Brown, W. M. (1967) 'The estimation of lymphocyte life span from studies of males treated with X-rays for ankylosing spondylitis' in 'Human Radiation Cytogenetics', ed. H. J. Evans, W. M. Court Brown, and A. S. McLean, p. 106. North-Holland, Amsterdam

Chalmers, R. A., Krömer, H., Scott, J. T., and Watts, R. W. E. (1968) Clin. Sci., 35, 353 (A comparative study of the Xanthine Oxidase inhibitors allopurinol and oxipurinol in man)

Elion, G. B. (1966) Ann. rheum. Dis., 25, 608 (Enzymatic and metabolic studies with allopurinol)

- Kovensky, A., Hitchings, G. H., Metz, E., ANd Rundles, R. W. (1966) Biochem. Pharmacol., 15, 863 (Metabolic studies of allopurinol, an inhibitor of xanthine oxidase)

Emmerson, B. T. (1966) Ann. rheum. Dis., 25, 622 (Discussion in Symposium on allopurinol, biochemistry and metabolism)

Fyfe, J. A., Miller, R. L., AND Krenitsky, T. A. (1973) J. biol. Chem., 248, 3801 (Kinetic properties and inhibition of orotidine 5'-phosphate decarboxylase. Effects of some allopurinol metabolites on the enzyme)

Hitchings, G. H. (1966) Ann. rheum. Dis., 25, 601 (Effects of allopurinol in relation to purine biosynthesis)

- (1969) FEBS Symposium, 16, 11 (Allopurinol—an inhibitor of xanthine oxidase: physiological and biochemical studies)

Kelley, W. M., AND WyngaArden, J. B. (1970) J. clin. Invest., 49, 602 (Effects of allopurinol and oxipurinol on purine synthesis in cultured cells)

, - (1972) In 'The Metabolic Basis of Inherited Disease', 3rd ed., ed. J. B. Stanbury, J. B. Wyngaarden, and D. S. Fredrickson, p. 969. McGraw-Hill, London

Krenitsky, T. A., Elion, G. B., Strelitz, R. A., AND Hitchings, G. H. (1967) J. biol. Chem., 242, 2675 (Ribonucleosides of allopurinol and oxoallopurinol. Isolation from human urine, enzymatic synthesis and characterization)

Nelson, D. J., AND Elion, G. B. (1975) Biochem. Pharmac., 24, 1235 (Metabolism of $6-{ }^{14} \mathrm{C}$ allopurinol: lack of incorporation of allopurinol into nucleic acids)

-, BugGe, C. J. L., KRASNy, H. C., AND Elion, G. B. (1973) Ibid., 22, 2003 (Formation of nucleotides of $6-{ }^{14} \mathrm{C}$ allopurinol and $6-{ }^{14} \mathrm{C}$ oxipurinol in rat tissues and effects on uridine nucleotide pools)

Norman, A., Sasaki, M. S., Ottoman, R. E., AND Fingerhut, A. G. (1965) Science, 147, 745 (Lymphocyte lifetime in women)

Rundles, R. W., Wyngaarden, J. B., Elion, G. B., Hitchings, G. H., and Silberman, H. R. (1963) Trans. Ass. Amer. Phycns, 76, 126 (Effects of a xanthine oxidase inhibitor on thiopurine metabolism, hyperuricaemia and gout)

Stevenson, A. C., San Roman, C., and Patel, C. R. (1973) Mutation Res., 19, 225 (Effects of amylobarbitone on the frequency of chromosomal aberrations in human lymphocytes determined by chlorambucil and melphalan in vitro) 